MEDITERRANEAN

\section{Treaty in store}

Sixteen Mediterranean states meeting in Barcelona earlier this month adopted a treaty on the protection of the Mediterranean against pollution which augurs well for a future "action plan'. Robert Allen reports

$A_{N}$ interval of only two years separates discussion of the first principles of the Mediterranean anti-pollution treaty and its signature. There are two main secrets of this success, which comes despite the sharp political differences of the participants (Spain, France, Monaco, Italy, Malta, Yugoslavia, Greece, Turkey, Cyprus, Syria, Lebanon, Israel, Egypt, Libya, Tunisia and Morocco).

One reason is the existence of a regional scientific and resource management body, the FAO's General Fisheries Council for the Mediterranean (GFCM). Arabs and Israelis, Greeks and Turks, have worked together on the Council for some years now, and are used to each other at the scientific and technical levels of government. Secondly, there is the United Nations Environment Programme (UNEP), which can not only bring governments together, but can locate, harness and coordinate legal, scientific and planning expertise scattered amongst numerous research institutes throughout the Mediterranean area and within the UN's many (often competing) specialised agencies. It is this capability which is the key to an ambitious "action plan" being developed by UNEP and the Mediterranean coastal states and involving cooperative action on four related fronts: scientific, legislative, institutional, and planning.

UNEP has set up seven research projects*, to run initially for two years, in order to establish a basic pollution profile of the Mediterranean. Each project will employ a network of laboratories, coordinated by UNEP, appropriate specialised agencies and a designated national research centre. So far, eight countries (Algeria, Cyprus, Israel, Italy, Lebanon, Malta, Spain and Yugoslavia) have nominated a total of 19 laboratories. Other countries are expected to nominate laboratories soon.

Where necessary, UNEP will provide

The 7 projects include: (1) baseline studic and monitoring of oil and petroleum hydrocarbons in marine waters (coordinated by carbons in marine waters (coordinated by
UNEP and the Intergovernmental Oceanographic Commission, IOC, of UNESCO) (2) baseline studies and monitoring of metals, particularly mercury and cadmium, in marine organisms and (3) of DDT and other of DDT and other chlorinated hydrocarbons in marine organism. -both coordinated by UNEP and the GFCM. analytical equipment and training in its use. It will also fund a common maintenance service to avoid long gaps in coordinated data collection. The International Atomic Energy Agency's Marine Radiation Laboratory in Monaco will help ensure compatibility of results by setting monitoring standards and providing intercalibration services.

The entire scientific programme is expected to cost some $\$ 10$ million (almost \$2 million from UNEP, and about $\$ 8$ million from participating governments). For this, the coastal states of the Mediterranean will obtain a reliable pollution profile of the marine environment, derived from simultaneous measurements of pollutant levels in the same taxa, at a large number of sampling points, with the same instrumentation. There will be a comprehensive range of strictly comparable national data from the entire region instead of the present hodgepodge of hard facts, circumstantial evidence and anecdote. Without this data, planning the rational exploitation of the Mediterranean commons would be virtually impossible. It would also be extremely difficult to maintain the present rapid legislative progress when more contentious issues are tackled.

The treaty consists of a convention supported by two protocols (one on dumping, the other on cooperation in the event of pollution emergencies, such as oil spills), but the next one to come, controlling pollution from landbased sources like rivers and coastal outfalls, is the one most likely to founder if the data base is insecure. Mediterranean nations will be confronted with the substantial economic differences between north and south and difficult trade-offs between one sector of a national economy and another. With non-Mediterranean upriver states also involved, a reliable pollution profile will be essential.

Much of the additional promise of the action plan lies in its integrated planning effort, which aims to help governments develop the shared resources of the Mediterranean in a sustainable fashion. Permanent channels for cooperative planning are being set up, based on a conception of the Mediterranean Sea area as an ecological unit. It sounds slightly over ambitious, but as Peter Thatcher, Director of UNEP's Geneva office, remarked, the adoption of the treaty demonstrates that the "political leaders of the Mediterranean have overcome the divisive issues of today in order collectively to preserve their common heritage and discharge their responsibilities to future generations".
CANADA

\section{New breed}

Canada's space programme was back on the nation's front page and television screens again briefly last month when the United States launched her neighbour's latest satellite, the CTS (communications technology satellite). David Spurgeon reports from Ottawa

CANADA's space programme has been one of her most successful scientific and technological ventures. Alouette $I$, the first satellite designed and built by a nation other than the United States or the Soviet Union, was still sending back useful ionospheric data 10 years after its launch in 1962. Three other Canadian made scientific satellites successfully followed that (Alouette II, ISIS-I, ISIS-II), and two domestic communications satellites (Anik-I and Anik-II) both continue to serve the country's communications needs, the former being the first such satellite to be used in a geostationary orbit.

Canada's vast distances, severe climate and scattered population have all meant that its space program has been oriented toward electronic methods of communication. The new CTS satellite follows this pattern. It is considered the forerunner of a new breed of highpowered communications satellites that will be able to transmit directly to small, low-cost earth stations sometimes in remote and otherwise inaccessible locations.

The CTS is in fact the most powerful communications satellite now operating, by virtue of three major subsystems. One of these is the travelling wave tube amplifier: its power output of 200 watts operating at an efficiency of $50 \%$ compares with the six watts at $30 \%$ efficiency of the current generation of tubes used in communications satellites. A pair of lightweight extendable antenna arrays carries enough solar cells to provide one kilowatt of power to the satellite; and a three-axis stabilization system, employing a fixed momentum wheel and hydrazine gas thrusters, maintains the aiming accuracy of the antenna and keeps the spacecraft oriented toward the sun (rather than letting the spacecraft spin as is usual) to ensure full use of solar power.

The CTS satellite is able to employ high power transmitters because it operates in a new frequency band of 12-14 gigaherz allocated for broadcast satellites. Current systems operate in the 4-6 gigaherz band, which is shared by other types of system on the ground. For this reason, satellite power levels must be limited to prevent interference 
with ground systems: previously this was a major factor dictating the use of large and expensive ground antennas.

Antenna diameters for the CTS range from 32 inches to 30 feet. The only other satellite designed to transmit high-quality colour television to small, simple ground stations is the ATS-6 (applications technology satellite), which was launched in 1974 and is now being used by the government of India to relay educational programs to isolated villages. The ATS- 6 must use a 30-foot antenna, and its effective radiated power is $53 \mathrm{DBW}$ (decibel watts), whereas CTS's is 59 DBW.

Canadian groups have designed 26 experiments for the CTS, to begin in May. They include:

- One-way video and two-way audio transmission to provide continuing medical education for doctors in remote areas.

- High-quality telephone links to and from remote camp-sites in the James Bay area, where a power dam is being built.

- Curriculum-sharing between Carleton University, Ottawa, and Stanford University, California, using a digital video compression technique.

- Provision of computer-communications networks for native peoples in Canada's isolated northern regions, and evaluation of the potential.

- Linking of two francophone communities in different parts of CanadaZenon Park, in Northern Saskatchewan, and a community in Quebec-for interchange of cultural and educational programs via two-way audio and video links. Other projects involve propagation measurements, a system for sharing telephone channels, and a fast frequency-shift keying system for highspeed digital data transmission.

The Canadian Broadcasting Corporation will try to demonstrate direct television reception from the satellite using simple, domestic-type equipment from laboratories in Japan and perhaps Europe. The satellite is also to be used for remote coverage of the 1976 Olympic Games equestrian competition at Bromont, Quebec. The signals would help in assessment of portable ground stations and reception and transmission from large, populated areas.

The United States and Canada will share equally in experiment time during the satellite's lifetime, using it on alternate days. If the experiments go as planned, the remote areas of many parts of the world-as well as Canada and the United States-may soon benefit from a multitude of communications services presently not economically feasible using conventional groundbased methods.

\section{USA}

WITH only one dissenting voice-that of Senator John V. Tunney of California-a subcommittee of the Joint Committee on Atomic Energy has produced a report giving full support to the liquid metal fast breeder reactor (LMFBR) programme and suggesting that "the time has come to end the discussion over whether or not [the United States] should have a breeder research and development program. Rather, national attention should be turned toward solving the outstanding problems associated with the program and its eventual commercialisation."

Senator Tunney identifies what he describes as a failure to deal adequately with many fundamental issues and questions surrounding the breeder programme, and in particular he objects to the subcomittee's attempts to see discussion of the programme stifled. That would be an abdication of responsibility, he says, as well as inconsistent with the subcommittee's conclusion that the building of the Clinch River Breeder Reactor in Tennessee would not represent "an irreversible commitment to commercialisation." (The Clinch River reactor, a 350-MW demonstration plant, is at present expected to be completed in 1983, at a cost of about $\$ 2,000$ million.)

The subcommittee, chaired by Conressman Mike McCormack of Washington, heard four main objections from opponents of the breeder reactor programme. It was argued that development costs would turn out to be prohibitive, that estimates by the Energy Research and Development Administration (ERDA) of indigenous uranium resources were too conservative, that energy demand would not grow as fast as projected, and that problems like plutonium toxicity and waste management would prove to be insoluble.

The subcommittee brushes those objections aside. One of its chief arguments in support of the LMFBR programme, for example, hinges on the suggestion that conventional reactors could start to run out of domestic supplies of uranium early in the twentyfirst century, and unless the plutoniumproducing capability of the breeder reactor is developed, the nuclear industry could grind to a halt. ERDA estimates, in fact, that there are about 3.6 million tons of uranium, available at a cost of less than $\$ 30$ per pound, in the United States. That is sufficient to guarantee a lifetime's fuel only to those reactors expected to be built before the mid-1990s.

- After 18 months of uncertainty, the future of Sacramento Peak Solar Observatory in New Mexico seems assured now that the National Science
Foundation (NSF) has agreed to provide $\$ 1.45$ million "to maintain the observatory at a productive level". The US Air Force, which has operated the observatory since 1952, will, however, still maintain a presence, and provide some of that money- $\$ 700,000$ in the first year of the new arrangements, and $\$ 450,000$ in the second. After that it is not clear what, if any, contribution it will make, or how the NSF will make up the shortfall.

Even with the Air Force chipping in a further $\$ 250,000$ for the salaries of those remaining and $\$ 250,000$ in grants, the observatory will, according to its acting Director, Dr Richard Dunn, have to sustain cuts of $15 \%$ in its present budget of $\$ 2.2$ million and $27 \%$ in its staff of 63 , as from June 30 .

The new funding scheme was hammered out by a committee chaired by Professor Martin Schwarzschild of Princeton University, and the NSF has now formally accepted it. Agencies such as NASA and ERDA were also involved in the discussions: NASA already has a group working at Sacramento Peak, and the observatory's research programme contains sufficient plasma physics, hydrodynamics and so on for ERDA to find it relevant to its own fusion research activities. (In fact at one time it seemed as if ERDA might pick up the tab for the observatory itself.) As the Air Force's contribution diminishes, the NSF will undoubtedly be looking to other agencies to stump up some of the extra money needed. The matter awaiting resolution now is precisely how the observatory will be managed once the Air Force relinquishes its overall responsibility.

The fifth annual report to Congress on marijuana and health shows that more than half of those between 18 and 25 have used the drug at some time, and that "what was once clearly statistically deviant behaviour has become the norm for this age group." The report also says that the correlation with level of education has now all but disappeared. The authors of the report, produced by the Department of Health, Education and Welfare, say, however, that the drug's long term effects are not yet properly understood. Another aspect of the drug's use seems to have altered: whereas users of marijuana were once less likely than non-users to consume alcohol, they now seem more likely to do so. "Frequently the two drugs are used simultaneously," says the report, "a combination that may be more hazardous than either used alone".

Roger Woodham Washington 